OPEN ACCESS

Edited by: Annette Gaertner, Evotec (Germany), Germany

Reviewed by:

Alice Davy,

Université Toulouse III Paul Sabatier,

France

Ali Shariati,

Stanford University, United States

${ }^{*}$ Correspondence:

Orly Reiner

orly.reiner@weizmann.ac.il

Received: 28 February 2017

Accepted: 01 June 2017

Published: 16 June 2017

Citation:

Gorelik A, Sapir T, Woodruff TM and Reiner O (2017) Serping1/C1 Inhibitor Affects Cortical Development in a Cell Autonomous and Non-cell Autonomous Manner.

Front. Cell. Neurosci. 11:169. doi: 10.3389/fncel.2017.00169

\section{Serping1/C1 Inhibitor Affects Cortical Development in a Cell Autonomous and Non-cell Autonomous Manner}

\author{
Anna Gorelik ${ }^{1}$, Tamar Sapir ${ }^{1}$, Trent M. Woodruff ${ }^{2}$ and Orly Reiner ${ }^{1 *}$ \\ ${ }^{1}$ Department of Molecular Genetics, Weizmann Institute of Science, Rehovot, Israel, ${ }^{2}$ School of Biomedical Sciences, The \\ University of Queensland, St Lucia, QLD, Australia
}

Current knowledge regarding regulation of radial neuronal migration is mainly focused on intracellular molecules. Our unbiased screen aimed at identification of non-cell autonomous mechanisms involved in this process detected differential expression of Serping1 or $\mathrm{C} 1$ inhibitor, which is known to inhibit the initiation of the complement cascade. The complement cascade is composed of three pathways; the classical, lectin, and the alternative pathway; the first two are inhibited by $\mathrm{C} 1$ inhibitor, and all three converge at the level of C3. Knockdown or knockout of Serping1 affected neuronal stem cell proliferation and impaired neuronal migration in mice. Knockdown of Serping1 by in utero electroporation resulted in a migration delay of the electroporated cells as well as their neighboring cells demonstrating a non-cell autonomous effect. Cellular polarity was also affected. Most importantly, expression of protein components mimicking cleaved C3 rescued the knockdown of Serping1, indicating complement pathway functionality. Furthermore, we propose that this activity is mediated mainly via the complement peptide C5a receptors. Whereas addition of a selective C3a receptor agonist was minimally effective, the addition of a dual C3aR/C5a receptor agonist significantly rescued Serping 1 knockdown-mediated neuronal migration defects. Our findings suggest that modulating Serping 1 levels in the developing brain may affect the complement pathway in a complex way. Collectively, our findings demonstrate an unorthodox activity for the complement pathway during brain development.

Keywords: Serping1, C1 inhibitor, innate immune complement pathway, neuronal migration, neuronal stem cell proliferation

\section{INTRODUCTION}

Deciphering what is the function of molecules expressed in the developing brain is a daunting task. Therefore, several years ago we embarked on an unbiased functional screen aimed at detecting molecules, which may affect neuronal migration in a non-cell autonomous way (Greenman et al., 2015). One of the differentially expressed genes detected in this screen was Serping1 (Serpin peptidase inhibitor, clade $\mathrm{G}$, member 1 ) encoding for the $\mathrm{C} 1$ inhibitor protein. $\mathrm{C} 1$ inhibitor is a member of the serpin family of protease inhibitors (reviewed by Davis et al., 2008). Similar to other serpin family protease inhibitors, the mechanism of inhibition requires a physical contact between the inhibitor and a specific protease, followed by a conformational change and formation of a covalent bond between the inhibitor and the serine residue which is part of the protease active site. $\mathrm{C} 1$ inhibitor has a key role in the complement pathway where it inhibits initiation proteases 
in either the classical pathway (C1r and $\mathrm{C} 1 \mathrm{~s}$ ) or the lectin pathway (MASP1 and MASP2) (Presanis et al., 2003; Parej et al., 2013). C1 inhibitor has additional important substrates that include contact system proteases (factor XII, plasma kallikrein), an intrinsic coagulation protease (factor XI) and the fibrinolytic proteases (plasmin, tissue plasminogen activator). However, based on our recent studies demonstrating the expression and function of the complement system in brain development (Coulthard et al., 2017; Gorelik et al., 2017), the current study on the role of Serping1 in the developing brain has been focused on its relationship within the complement pathway. In addition to protease inhibition, $\mathrm{C} 1$ inhibitor can physically bind and functionally affect the interaction between complement factor $\mathrm{C} 3 \mathrm{~b}$ and complement factor $\mathrm{B}$ and thus to interfere also with the alternative pathway (Jiang et al., 2001). Additional functional interactions include different extracellular matrix components, endothelial cells and leukocytes, gram negative endotoxin, and several infectious agents (reviewed by Davis et al., 2008).

C1 inhibitor has been associated with several diseases. Addition of $\mathrm{C} 1$ inhibitor has been shown to be neuroprotective in case of ischemic injury (De Simoni et al., 2004; Storini et al., 2005; Gesuete et al., 2009; Heydenreich et al., 2012). However, it is likely that the neuroprotection is not mediated solely via the activity of $\mathrm{C} 1$ inhibitor on the complement pathway. Expression of multiple components of the complement pathway, including C1 inhibitor has also been demonstrated in Alzheimer's disease, which may reflect ongoing inflammation in the brains of the patients (Walker et al., 1995; Veerhuis et al., 1998; Yasojima et al., 1999). It has been suggested that reduced levels of C1 inhibitor may be a biomarker for Alzheimer's disease (Akuffo et al., 2008; Cutler et al., 2008; Chiam et al., 2015; Muenchhoff et al., 2015; Morgan et al., 2017).

Deficiency of $\mathrm{C} 1$ inhibitor is a rare autosomal dominant disease known as Hereditary angioedema (HAE) with an estimated prevalence of 1:50,000, where about 25\% of the patients exhibit de novo mutations (Bowen et al., 2010). Patients with HAE may experience recurrent edema of the skin and submucosal tissue associated with pain syndromes, nausea, vomiting, diarrhea, and life-threatening airway swellings. Risk of dying from airway obstruction if left untreated is significant. Additional symptoms may present as well and the manifestations and severity of HAE are highly variable. In this disease, the low levels of active $\mathrm{C} 1$ inhibitor in the plasma leads to unregulated activation of the complement and contact cascades and the development of angioedema with its associated complications. Complement system activation results in decreased levels of C4 and C2, while contact system activation results in cleavage of high molecular weight kininogen. Studies conducted in a mouse model for this disease revealed that both homozygous and heterozygous mice exhibit increased vascular permeability in comparison with wild-type littermates (Han, 2002). They have further shown that this phenotype is mediated through the bradykinin type 2 receptor.

In contrast to its roles in innate immunity, very little is known about the expression and functional activity of Serping1 in the developing brain. A study examining single cell RNA expression in the E14 developing mouse brain revealed that Serping1 is expressed in subventricular zone (SVZ) basal progenitors (Kawaguchi et al., 2008). In this study, we therefore set out to investigate the role of this interesting molecule in the developing cortex and how its function there relates to the complement pathway.

\section{RESULTS}

\section{Serping1 Is Expressed in the Developing Brain}

Serping1 was detected in developing mouse brains (E14.5E17.5) in an unbiased screen aimed at identifying molecules which may affect neuronal migration in a non-cell autonomous way (Greenman et al., 2015). The screen was designed to highlight changes between genes expressed in stalled cells that acquire either a bipolar (following Dclk shRNA treatment) or a multipolar appearance (following Dclk shRNA treatment). The results of the screen showed that the levels of Serping1 were 2.10 -fold higher in Dclk shRNA vs. Dcx shRNA. The differences at the mRNA level were verified by realtime qPCR (59.6 \pm $1.5 \%$ in Dcx shRNA compared to Dclk shRNA, $n=6$, Student's t-test, $p=0.0047$, Supplementary Figure 1A) and were also recapitulated at the protein level, with an elevation of 159.6 $\pm 8.82 \%$ in SERPING1 protein in Dclk shRNA-treated brains vs. $D c x$ shRNA-treated brains $(n=5$, Student's t-test, $p=$ 0.041, Supplementary Figure 1A). Following these results we next examined Serping1 mRNA expression in the developing cortex using real-time qPCR (Supplementary Figure 1B). When the expression was normalized to that observed on E13.5, similar levels were noted on E14.5, followed by an observed decreased expression on E16.5 and E18.5. RNA in situ hybridization data from E14.5 brain section taken from (http://www.genepaint.org) demonstrated that Serping1 mRNA is expressed in the developing cortex, where the highest expression levels are seen in the SVZ as previously reported (Kawaguchi et al., 2008). However, in addition Serping1 mRNA was expressed in the ventricular zone, and lower levels of expression could also be observed in the cortical plate (Supplementary Figure 1C). The timing and pattern of Serping1 expression suggested that this gene may participate in neuronal stem cell proliferation.

\section{Serping1 Affects Neuronal Stem Cell Proliferation}

To investigate the role of Serping1 in regulation of neuronal stem cell proliferation during mouse embryonic brain development two models were used. In the first, we knocked-down gene expression using in utero electroporation of an shRNA expressing plasmid, and in the second we generated knockout embryos using CRISPR/Cas9 gene editing technology (Ran et al., 2013; Wang et al., 2013) (Supplementary Figures 2A,B). Serping1 shRNA effectively reduced the levels of Serping 1 mRNA by $37.5 \pm 8.9 \%$ in comparison to control (qPCR, $n=9$, Student's $t$-test $p=0.00012$ ), as well as SERPING1 protein in the developing brain (52.7 \pm $5.6 \%$ compared to control, $n=4, p=0.0064$ ). Neuronal stem cell proliferation was tested by application of a short IdU pulse, which is incorporated during $\mathrm{S}$ phase following by immunostaining 
of embryonic brain sections using the respective antibodies. Embryos were in utero electroporated at E13 and analyzed at E14. The analysis was targeted at the IdU/GFP positive cells, which were likely to receive the respective shRNA plasmids. There was a statistically significant difference between the IdU/GFP double positive cells, where the introduction of Serping1 shRNA reduced the number of cells in S-phase (Student's t-test $21 \pm 2.2 \%$ vs. $14.5 \pm 1.4, n=5, p=0.037$, Figures 1A,B). In addition,
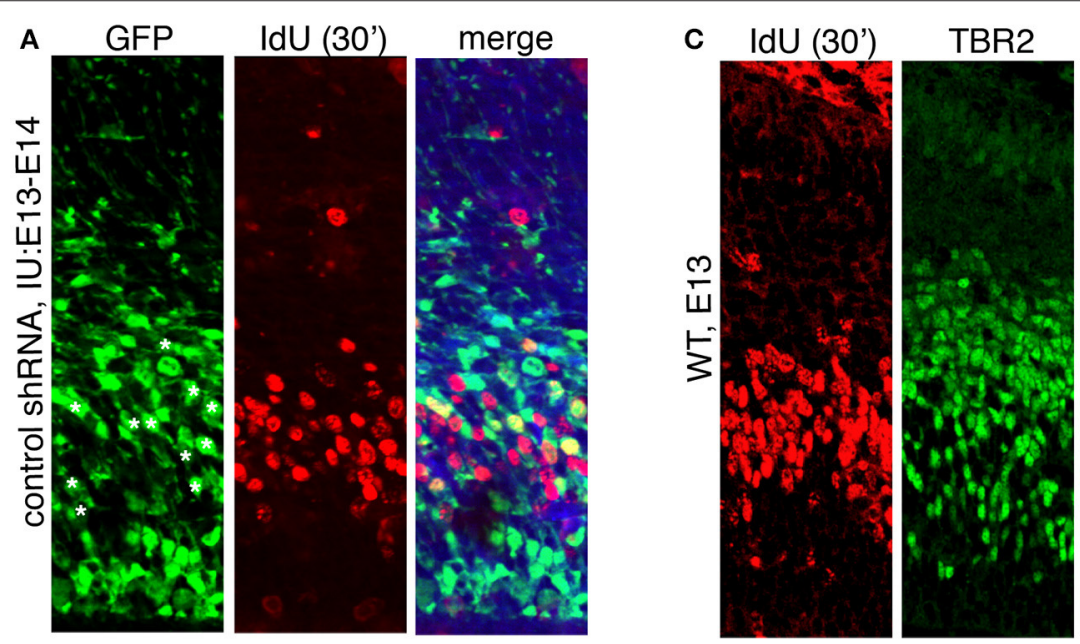

merge
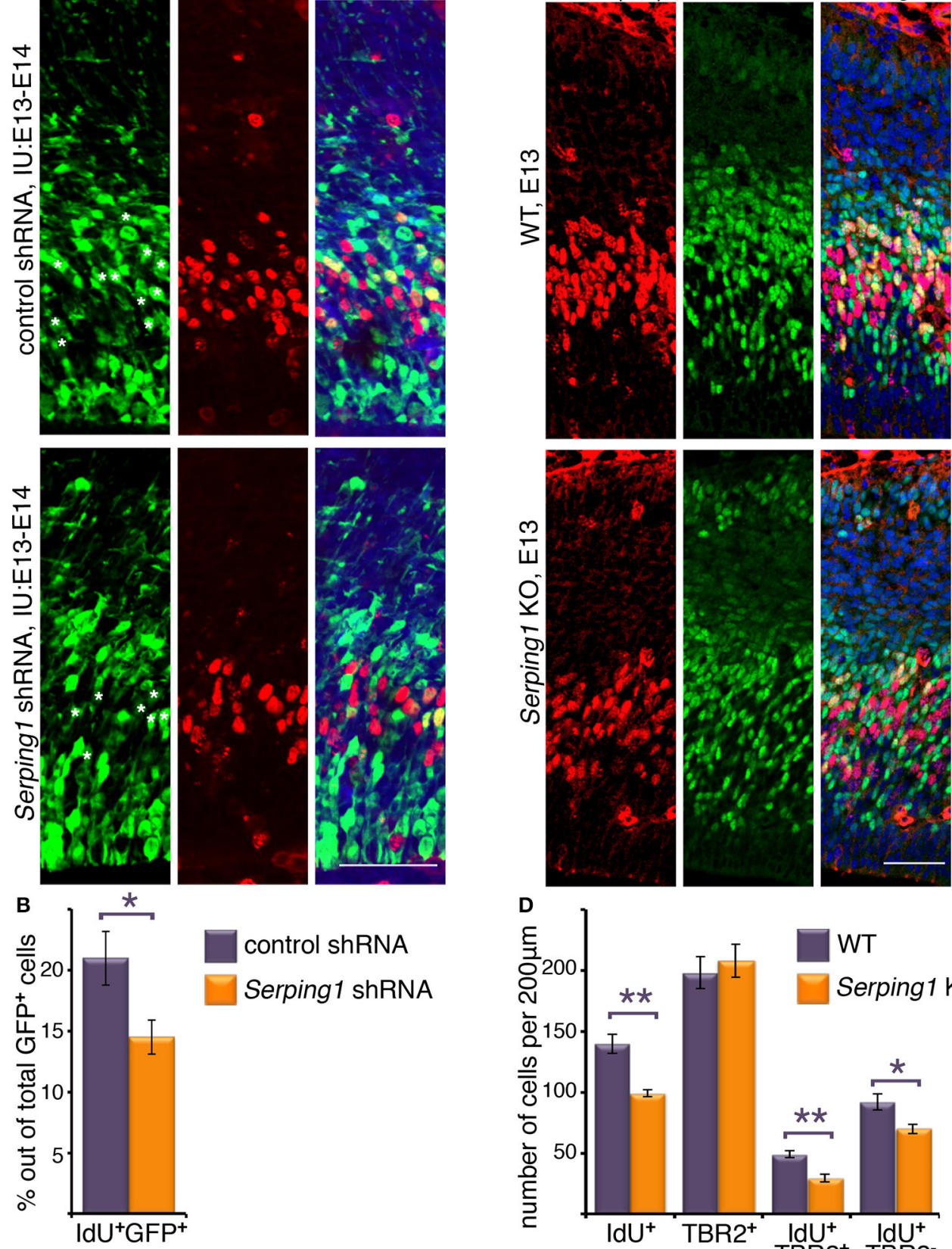

control shRNA

Serping1 shRNA

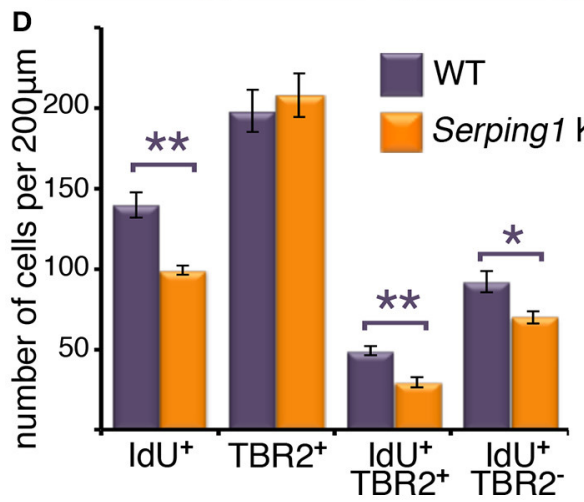

FIGURE 1 | Serping1 affects neuronal stem cell proliferation. (A,B) Embryonic brains were in utero electroporated with control shRNA or Serping1 shRNA at E13 and at E14 were treated with IdU for 30 min. The brains were cryosectioned and immunostained with anti-IdU antibodies. GFP labeled the electroporated cells. IMARIS software was used to count the total GFP-positive cells and the double GFP- and IdU-positive cells within slices of the same size (230 $\mu \mathrm{m}$ in length). Double-positive cells are marked with white asterisks in the GFP panel. The relative proportion of double-positive cells to the total number of GFP-positive cells was calculated (B, Student $t$-test, $n=5$, $\left.{ }^{*} p<0.05\right)$. (C,D) Brains of E13 Serping1 $\mathrm{KO}$ and littermate WT were treated with IdU for 30 min. The brains were cryosectioned and immunostained with anti-IdU and anti-TBR2 antibodies. The number of IdU-positive, TBR2-positive, double positive, IdU-positive TBR2-negative cells was counted (D) in identical areas of the cortices (200 $\mu \mathrm{m}$ in length). Welch's $t$-test, $n=6,{ }^{*} p<0.05,{ }^{* *} p<0.01$. The scale bars are $50 \mu \mathrm{m}$. 
embryos in which Serping1 was knocked out were generated. Brain sections were immunostained for IdU and also for TBR2, a basal progenitors marker, using the respective antibodies (Figure 1C). Similar to the trend observed in case of Serping1 knockdown, a significant reduction in the number of IdU positive cells was noted (Student's $t$-test, Welch-corrected $140 \pm 8$ vs. $99 \pm$ 2.7, $n=6, p=0.0028$, control and Serping1 KO, respectively, Figures 1C,D). Whereas, the total number of TBR2 positive cells did not differ between the wild-type and the knockout, there was a clear difference in the number of IdU/TBR2 positive cells, where less cells were double labeled in the KO (Student's $t$ test, $49 \pm 3.13$ vs. $29 \pm 2.9, n=5,6$, respectively, $p=0.0012$, Figures 1C,D), thus suggesting that in the Serping1 KO there is a reduction of intermediate progenitors at E14. In addition, the number of IdU positive/TBR2 negative cells was also decreased in the Serping1 KO (Student's t-test, $92.2 \pm 6.8, n=5$ vs. $69.83 \pm 3.85, n=6, p=0.0154$, Figures 1C,D). To check whether the observed differences resulted from alterations in $\mathrm{S}$ phase duration, double labeling using two thymidine analogs was performed. Embryos were in utero electroporated at E13 with either control shRNA or Serping1 shRNA. On E14 the cells were labeled with EdU for the duration of $2.5 \mathrm{~h}$ and then with IdU for $0.5 \mathrm{~h}$ (Supplementary Figure 3). No significant differences in the proportion of EdU/GFP double positive cells $(14.1 \pm 0.5 \%$ in Serping1 shRNA vs. $16.5 \pm 1.6 \%$ in control, $n$ $=7$, Sidak's multiple comparison test) or IdU/EdU/GFP triple positive cells $(7.8 \pm 0.8$ vs. $10.6 \pm 0.6 \%, n=7)$ thus suggesting that the cell cycle length was not affected. The proportion of IdU/GFP double positive cells was reduced in Serping1 shRNA consistent with previous experiments $(17.4 \pm 1.2 \%$ vs. $23.5 \pm$ $0.9, n=7)$. In addition significantly more GFP only positive cells were noted in case of Serping1 shRNA treatment, suggesting that these cells were not actively in S-phase during the tested period (76.3 \pm 1.1 vs. $70.6 \pm 1.5 \%, n=7)$. Collectively, our results suggest that knockdown or knockout of Serping1 results in a reduction in the number of cycling cells of both ventricular zone (radial) and intermediate (basal) progenitors during cortical development.

\section{Serping1 Affects Radial Migration in a Cell Autonomous and Non-cell Autonomous Way}

The possible role of Serping1 in regulation of radial migration was investigated by knockdown of the gene using in utero electroporation of Serping1 shRNA and by studying knockout embryos generated by CRISPR/Cas9 gene editing. Serping1 shRNA significantly impaired radial neuronal migration (compare control in Figure 2A to Figure 2B), and this phenotype was partially rescued following the addition of Serping1 shRNA-resistant form (Serping1 ${ }^{\text {res}}$ ) (Figure 2C). The position of the GFP positive cells was quantified in five bins across the width of the cortex. A two-way ANOVA demonstrated that the number of cells in the different bins differed between the control and Serping1 shRNA in four out of five bins (Figure 2D). Addition of Serping $1^{\text {res }}$ restored the level of SERPING1 protein to control levels (data not shown) and significantly improved the position of the cells in three out of four bins (Figure 2D). Neuronal migration impairment was also detected in Serping1 knockout embryos in comparison with wild type litter-mates (Figures 2E,F quantified in Figure 2G). Neurons were birthdated with a uridine analog at E14.5 and their relative position in the cortex was scored at E18. The distribution of neurons along the width of the cortex significantly differed in three out of five bins (Figure 2G). Next, the identity of the stalled cells at E18 was examined (Figures 2 H-L). Although most of the Serping1 shRNA treated cells have not reached the cortical plate (compare the GFP+ cells in Figure 2I vs. Figure $\mathbf{2 H}$ ), the majority express the superficial layer marker CUX1 and not the deep layer marker TBR1 (Figures 2J-L). In the postnatal brain (at P8), Serping1 shRNA treated cells did reach the cortical plate, nevertheless, even in low magnifications, it is possible to observe that their morphology differs from that observed in the control (Figures 2M,N).

Next, the possibility that Serping1 may affect neuronal migration in a non-cell autonomous way in addition to the cell autonomous effect observed above was examined (Figure 3). The experimental design included labeling and monitoring two distinct populations in the developing embryonic brain by consecutive electroporation. The first population was treated with shRNA (at day E13) and labeled with GFP. The position of the first population reflected cell autonomous effects. The second cell population was electroporated with a red fluorescent protein only a day later (E14) and thus its behavior is presumed to reflect non-cell autonomous effects emanating from the first (green) population. We concluded that the effect of Serping1 knockdown was both cell autonomous and non-cell autonomous; it affected the genetically modified cells as well as the neighboring cells. Although in the control, later born cells (red) successfully migrated through the layer of previously born cells (green) treated with control shRNA (Figures 3A-C, quantification in Figures $\mathbf{3} \mathbf{A}^{\prime}, \mathbf{B}$ ') , the migration of the red cell population through the green cell layer, which was treated with Serping1 shRNA, was markedly impaired (Figures 3D-F,D,E', compare Figure 3B and Figure 3B' to Figure 3E and Figure 3E', the correlation of the relative position of the red cells in $B$ and $\mathrm{E}$ is -0.03). When the order was reversed, the later born Serping1 knockdown cells did not impair the motility of earlier born control green (Figures 3G-I,G', H' the correlation of the relative position of the red cells in $B$ and green cells in $G$ is 0.92) or red positive cells (Figures $\mathbf{3} \mathbf{J}-\mathbf{L}, \mathbf{J}, \mathbf{K}$, the correlation of the relative position of the red cells in Figure $\mathbf{3 B}$ and red cells in Figure 3J is 0.76). The observed non-cell autonomous effect was not due to residual, stable Serpingl shRNA in the cortex. Serping1 shRNA and GFP plasmids were injected into the cortex at E13 but not electroporated, a day later, a red fluorescent plasmid was injected and electroporated. No GFP positive cells were noticed at E18 and no neuronal migration impairment was noted (Figures 3M-O,M',N'). A non-cell autonomous effect was also observed using a different approach. The cells neighboring in utero E13 electroporated cells were labeled at E14 by a uridine analog, and their position in the cortex was analyzed at E18. The relative distribution of the IdU labeled cells in the in utero electroporated side of the 

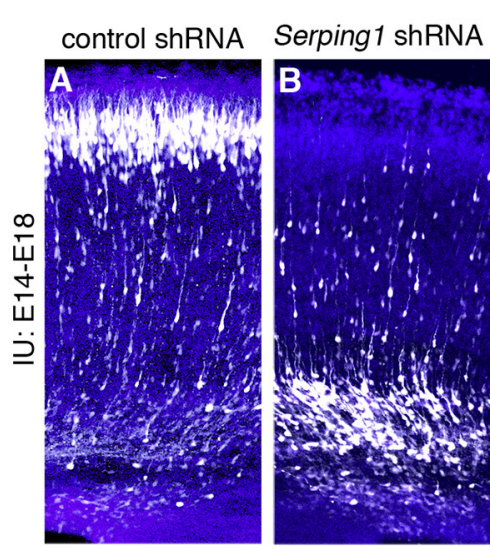

Serping 1 shRNA

+ Serping $1^{\text {res }}$
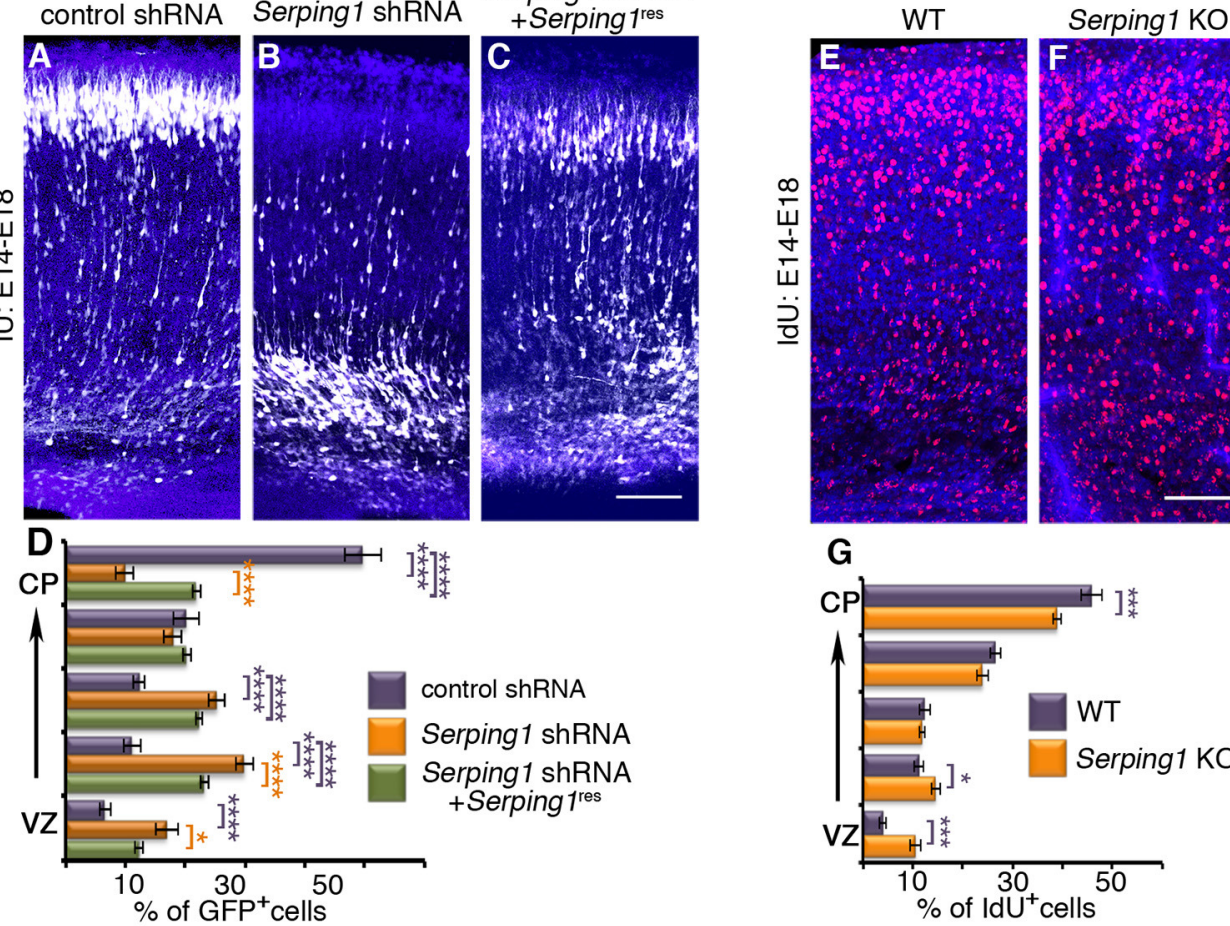

control shRNA

Serping 1 shRNA

Serping1 shRNA

+ Serping $1^{\text {res }}$
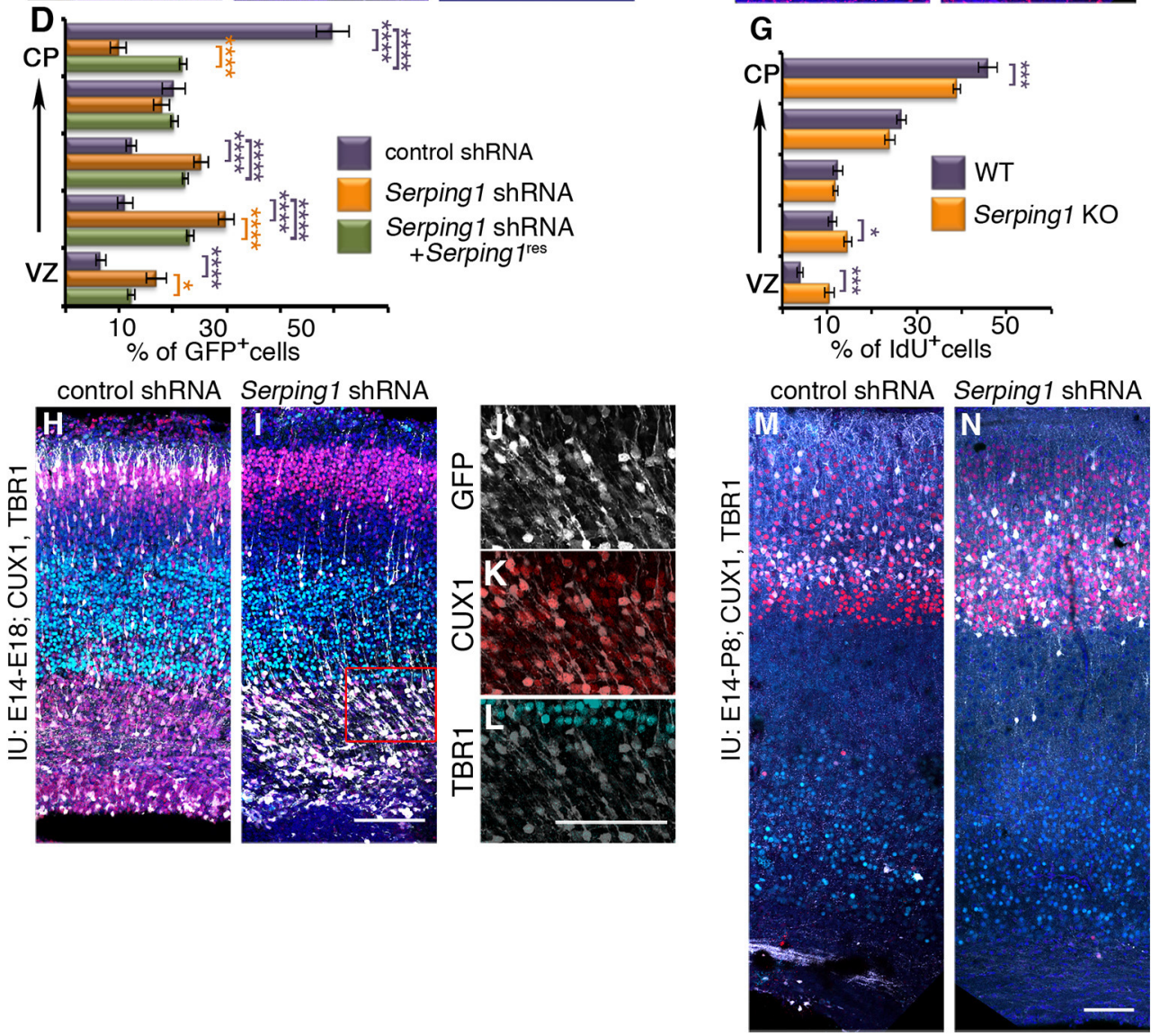

FIGURE 2 | Serping1 affects neuronal migration. (A-D) Serping1 knockdown affects neuronal migration. Brains were electroporated in utero (E14-E18) with control shRNA (A), Serping1 shRNA alone (B) or in combination with Serping1 resistant to the shRNA (C). (D) The position of GFP+ neurons across the width of the cortex was analyzed and is shown in 5 bins (from the VZ to the CP). The statistical significance of comparison to control is shown in violet. The statistical significance of comparison to Serping1 shRNA is shown in orange. Two-way ANOVA, $n=11,{ }^{*} p<0.05,{ }^{* * *} p<0.0001$. (E-G) Serping1 KO affects neuronal migration. Serping1 $\mathrm{KO}$ embryos (F) and littermate controls (E) were labeled with IdU on E13 and the position of IdU-positive neurons was analyzed on E18 and is shown (G) in 5 bins (from the VZ to the CP). Two-way ANOVA, $n=12,{ }^{\star} p<0.05,{ }^{* * *} p<0.001$. (H-L) The identity of electroporated cells. Slices of control shRNA and Serping1 shRNA were immunostained with anti-CUX1 (red) and anti-TBR1 (light green) antibodies. Serping1 shRNA arrested cells are shown in higher magnification (J-L). (M-N) Postnatal positioning and the identity of control and Serping1 knockdown cells. Brains electroporated in utero on E14 with control shRNA (M) or Serping1 shRNA (N) were immunostained at postnatal day 8 (P8) with anti-CUX1 (red) or anti-TBR1 (light-green) antibodies. The scale bars are $100 \mu \mathrm{m}$.

brain differed significantly from the relative distribution of IdU labeled cells on the non-in utero electroporated side of the brain (Supplementary Figure 4A-B', three out of five bins showed significant differences Supplementary Figure 4C). Taken together, our data suggest that SERPING1 participates in regulation of radial neuronal migration in 


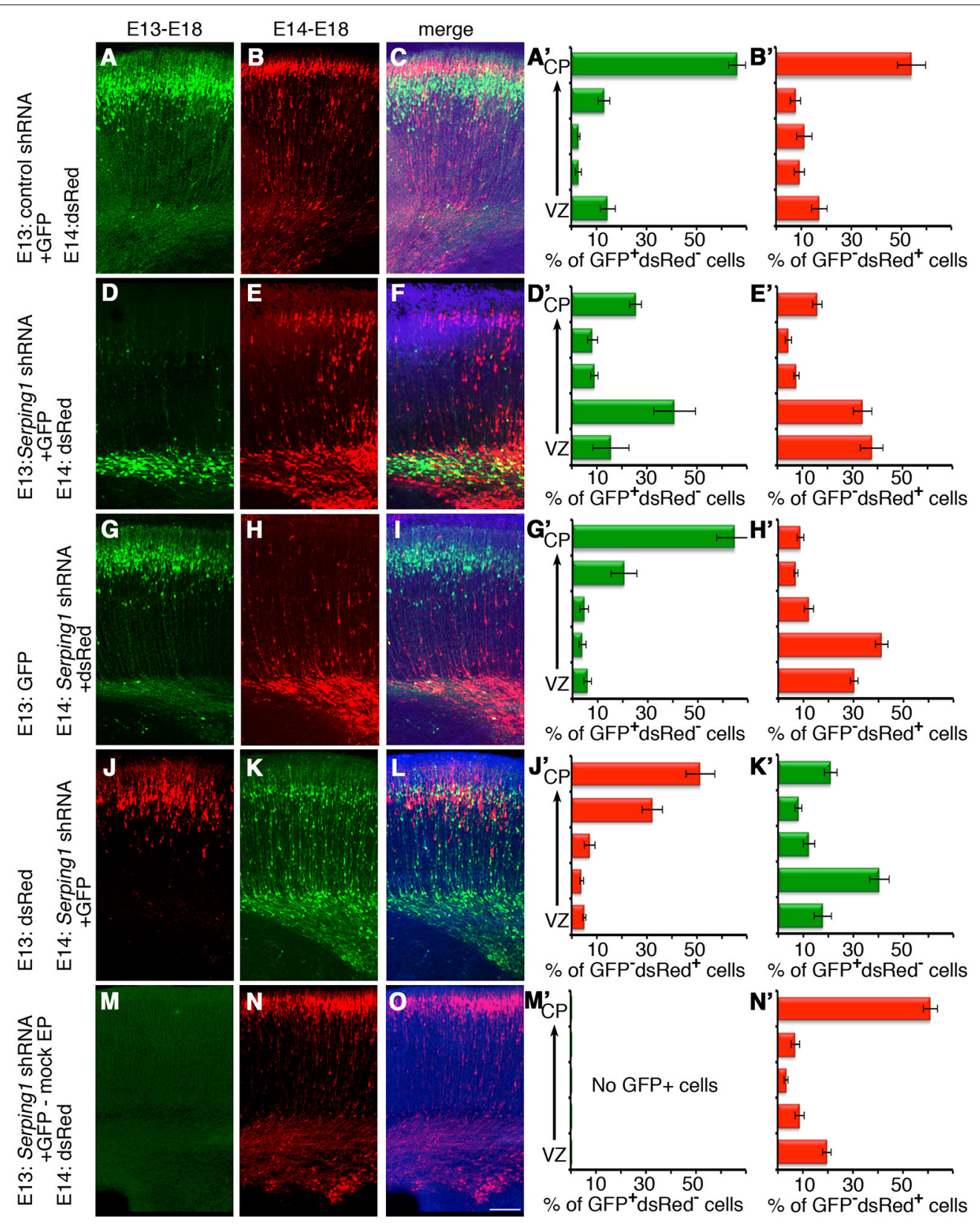

FIGURE 3 | Non-cell autonomous effects of Serping1 shRNA. (A-F) Serping1 shRNA exhibits non-cell autonomous effects. Brains were in utero electroporated with control shRNA (A-C) or Serping1 shRNA (D-F) together with GFP on E13, followed by electroporation with dsRed on E14. The analysis was performed on E18. GFP-positive neurons (A,D), dsRed-positive neurons (B,E), and merged images (C,F) are shown. The position of GFP-positive dsRed-negative (A', $\mathbf{D}^{\prime}$ ) and dsRed-positive GFP-negative (B',E') cells was analyzed. The distribution of the dsRed-positive GFP-negative cells (E,E') demonstrates non-cell autonomous effect of Serping1 shRNA (compare to $\left.\mathbf{B}, \mathbf{B}^{\prime}\right) . n=6$. (G-O) Controls of non-cell autonomous experiment. (G-L) The population of the neurons can be easily segregated as demonstrated by the inverse order of electroporation. Brains were electroporated with GFP on E13 and with Serping1 shRNA with dsRed on E14 (G-I), or vice versa brains were electroporated with dsRed on E13 and with Serping1 shRNA with GFP on E14 (J-L). Cells treated with shRNA demonstrated impaired migration (H', K'). In both conditions cells without shRNA had no defect in migration (G,G', J, J'). (M-O) Control experiment demonstrates that there is no left-over of the plasmids in between electroporations. Serping1 shRNA together with GFP were injected but not electroporated into the ventricle on E13. dsRed was electroporated on E14. On E18 there are no GFP-positive cells (M,M'). The migration of dsRed-positive cells was not affected (N,N'). The scale bar is $100 \mu \mathrm{m}$.

a cell autonomous as well as in a non-cell autonomous fashion.

Closer inspection of the stalled cells revealed that they exhibit long processes (Figures 4A,B). In addition, it appeared that wildtype cells that were in close vicinity to the Serping1 shRNA treated cells also exhibited very long processes (Figure 4C). The length of the leading edge of individual cells was quantified and the leading-edge length of either Serping1 shRNA treated cells or of their red neighbors significantly differed from the values of the controls (Figure 4D). Therefore, western 


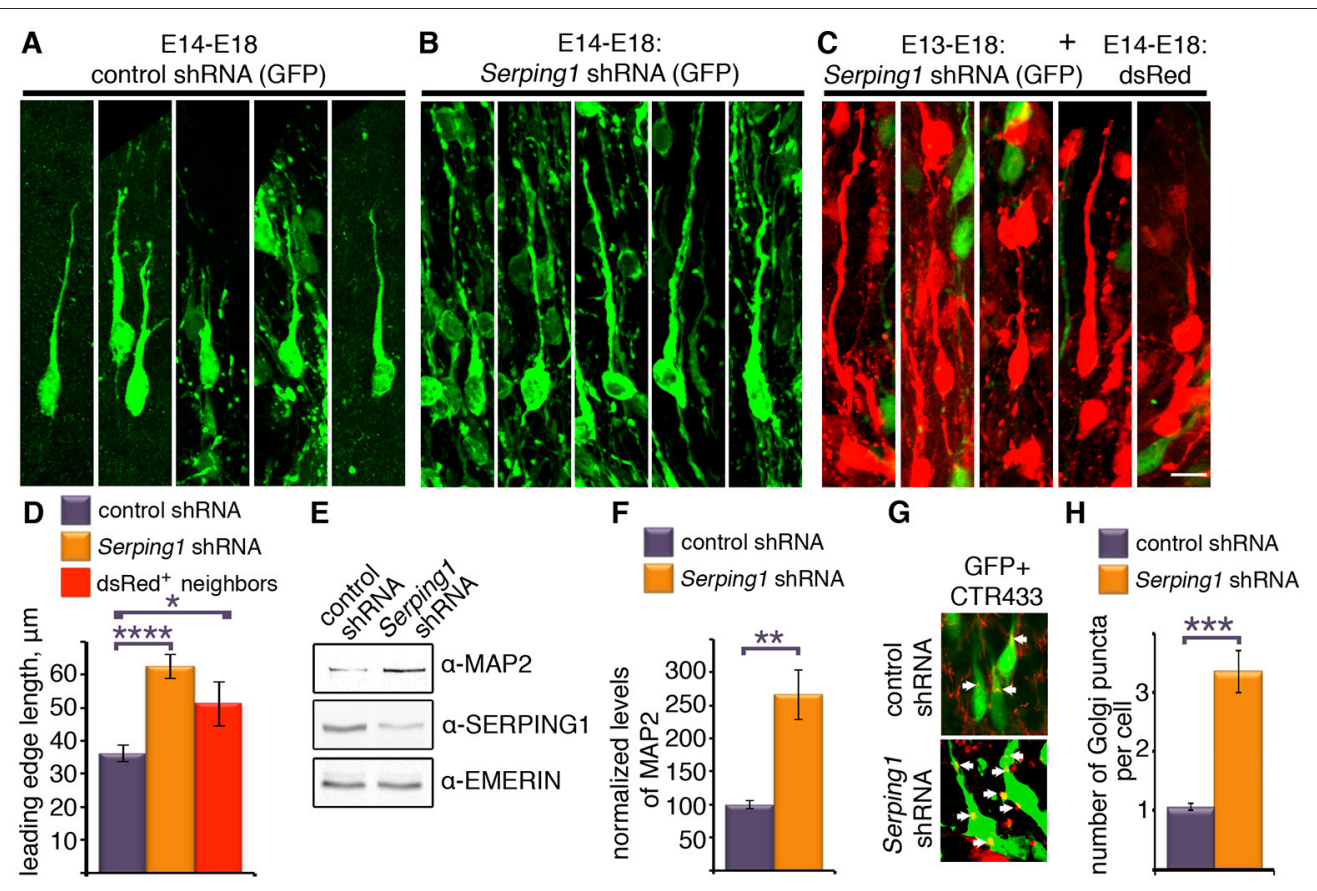

FIGURE 4 | Serping1 influences neuronal morphology in a cell-autonomous and non-cell autonomous way. (A-D). Brains were in utero electroporated with control shRNA (A) or Serping1 shRNA (B) together with GFP (E14-E18). Representatives of individual cells from the IZ are shown (C). Brains were in utero electroporated with Serping1 shRNA on E13 and with dsRed on E14. DsRed positive cells arrested in IZ (E18) are shown. The length of the leading edge was measured on high-magnification 3D reconstruction images with ImageJ software. The lengths of the leading edges were compared between the conditions (D). One-way ANOVA, Turkey HSD, $n=16,{ }^{\star} p<0.05,{ }^{\star \star * \star} p<0.0001$. The scale bar is $10 \mu \mathrm{m}$. (E,F) Brains were in utero electroporated with control shRNA or Serping1 shRNA together with GFP (E14-E17). The electroporated areas were dissected under fluorescent binocular. The dissected areas were lysed and western blotted using anti-MAP2, anti-SERPING1 and anti-EMERIN antibodies. The levels of MAP2 were normalized to EMERIN. Levels of MAP2 relative to control (in \%) are presented (F). $n=3$, Student $t$-test, ${ }^{* \star} p<0.01$ (G-H). Golgi analysis in Serping1 knockdown compared to control. Control shRNA or Serping1 shRNA electroporated brain sections (E14-E18) were immunostained with Golgi marker antibodies (CTR433). Immunostaining of the Golgi are presented together with GFP. White arrows show position of Golgi. The scale bar is $10 \mu \mathrm{m}$. Quantification of the number of Golgi clusters per cell $\left(n=20\right.$, Student $t$-test) are shown $\mathbf{( H )}{ }^{* * *} p<0.001$.

blot analyses were conducted using several antibodies. Most strikingly, the levels of MAP2 increased more than 2.5-fold in Serping1 shRNA brain lysates (Figures 4E,F). No differences were noted for phospho-DCX and phospho-ERK antibodies. MAP2 (microtubule-associated protein 2) is a prominent microtubule associated protein expressed in the developing brain (Dinsmore and Solomon, 1991). The increased levels of MAP2 are consistent with the observed morphological changes. Although the elongated Serping1 shRNA treated cells appeared to be bipolar, immunostaining with a Golgi marker that appears as a packed cluster at the basal side of nucleus in the migrating bipolar control cells, revealed that the cells have not completed polarization. On average more than three Golgi clusters were noted in the treated cells instead of one observed in control cells (Figures 4G,H).

\section{Serping1 Is Part of the Complement Pathway}

Finally, we evaluated whether the developmental effects of Serping1, were due to its role within the complement pathway. Serping1, or C1 inhibitor, participates in the three activation arms of the complement system. It covalently binds and inhibits the activity of the $\mathrm{C} 1 \mathrm{r}$ and $\mathrm{C} 1 \mathrm{~s}$ serine proteases that are involved in initiation of the classical pathway (hence the origin of the name $\mathrm{C} 1$ inhibitor). However, it also covalently binds and inhibits the activity of the closely related MASP1 and MASP2 proteases, which initiate the lectin pathway. It can also physically bind and functionally affect the interaction between complement factor $\mathrm{C} 3 \mathrm{~b}$ and complement factor $\mathrm{B}$, and thus to interfere also with the alternative pathway(see schematic presentation in Figure 5). Therefore, Serping1 or C1 inhibitor inhibits all the activation arms of complement. Complement activation will lead to an increase in the levels of cleaved C3, which can be detected by anti-C3b antibodies. Brain lysates from Serping1 shRNA treated and control treated were therefore analyzed by western blot using anti-C3b antibodies (Figure 6A). Contrary to our expectations, a small yet significant reduction in the levels of $\mathrm{C} 3 \mathrm{~b}$ were noted (Figure 6B). It was postulated that pathway activation may result in rescue of neuronal migration impairment and we next queried the effect of C3 mimicry cleavage products (scheme in Figure 6C) and either the single $\mathrm{C} 3 \mathrm{a}$ receptor $(\mathrm{C} 3 \mathrm{aR})$, or the dual $\mathrm{C} 3 \mathrm{aR} / \mathrm{C} 5 \mathrm{a}$ receptor $(\mathrm{C} 5 \mathrm{aR})$ agonists in combination with Serping1 shRNA. As previously observed, Serping1 shRNA impairs neuronal migration (Figures 6D,D'). When the C3a mimicry product was expressed in utero together with Serping1 shRNA no effect was observed (Figures 6E-E'). 


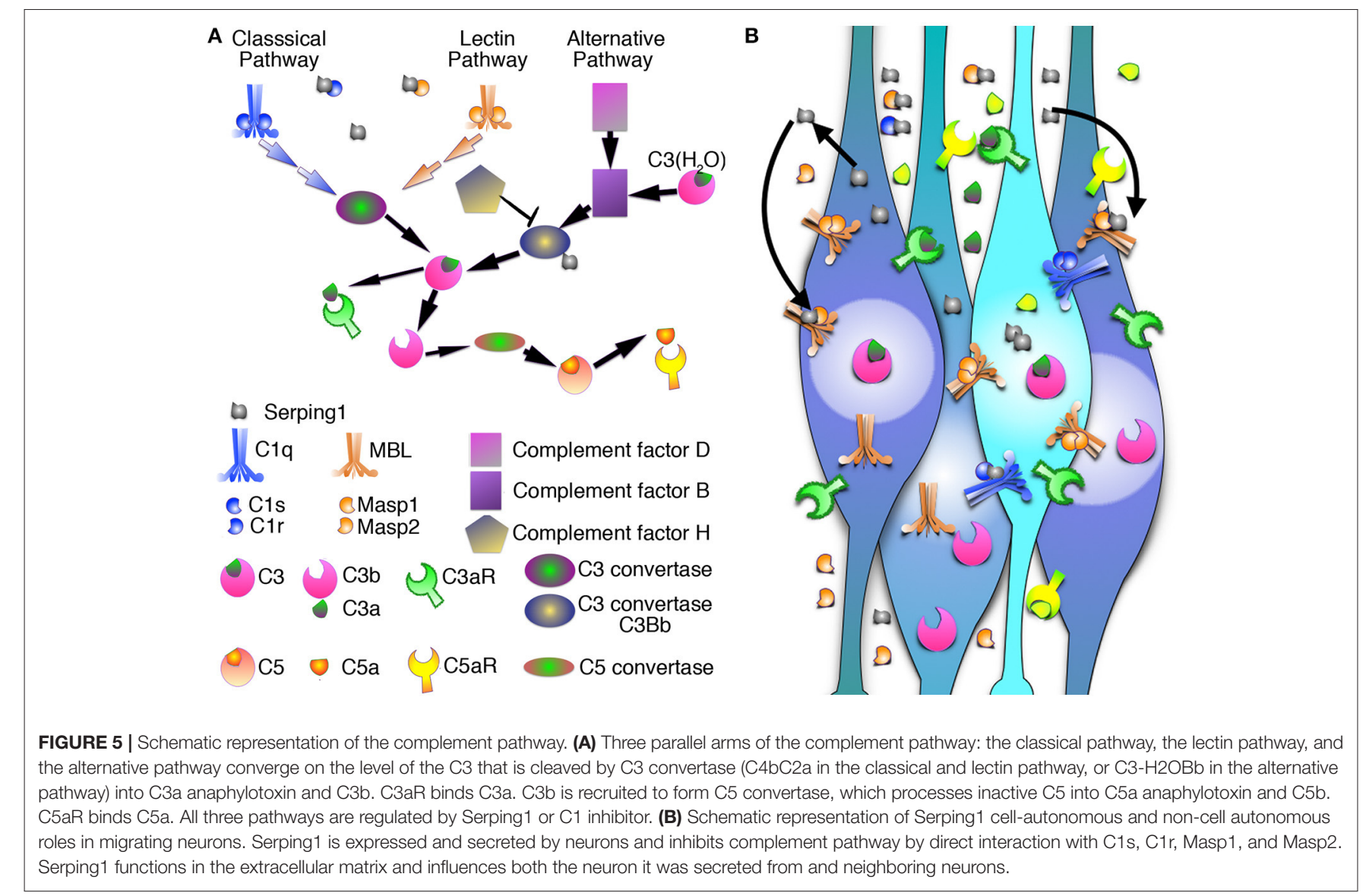

The effect of the addition of the downstream C3aR agonist corroborated this finding, which minimally affected the proper position of migrating neurons (Figures $6 \mathbf{F}, \mathbf{F}^{\prime}$ ). Addition of the $\mathrm{C} 3$ mimicry cleavage products $\mathrm{C} 3 \mathrm{~b}$ alpha or less effectively $\mathrm{C} 3 \mathrm{~b}$ beta, significantly improved neuronal migration (Figures 6G-H'), suggesting that activation of $\mathrm{C} 3$ cleavage is required for proper neuronal migration. Furthermore, the addition of the dual $\mathrm{C} 3 \mathrm{aR} / \mathrm{C} 5 \mathrm{aR}$ agonist completely restored neuronal positioning to control levels (Figures 6I-I'), supporting that downstream complement activation at the level of $\mathrm{C} 5 \mathrm{a}$ is required for proper migration of pyramidal neurons to the cortical plate.

\section{DISCUSSION}

\section{The Role of Serping1 in the Developing Cortex}

Collectively our findings suggest that Serping1 (C1 inhibitor) is important for cortical development at several stages. At early stages of cortical development Serping1 is important for the proliferation of neuronal stem cells. A decrease was noted in the number of cells in $S$ phase that include both radial glia and intermediate progenitors. The effect may be transient since the total number of TBR2 positive basal progenitors, cells was not affected. Serping1 has been reported to be expressed in the SVZ basal progenitors (Kawaguchi et al., 2008), yet our study is the first demonstrating a direct role for this gene product in neuronal stem cell proliferation. Our previous studies showed that knockdown or knockout of other components of the complement pathway affects neuronal stem cell proliferation in different ways. Knockout of C3 increased the number of mitotic intermediate progenitors (phospho-Histone positive), whereas knockdown of Masp1 did not affect the number of progenitors in $\mathrm{S}$ phase (IdU positive) and knockdown of Masp2 resulted in a statistically significant increase in the number labeled progenitors (IdU positive) (Gorelik et al., 2017). These highly variable outcomes may suggest that within neuronal stem cell progenitors there is not a linear relationship between changes in the components of the complement pathway and neuronal stem cell proliferation. Alternatively, it is possible that the spatiotemporal expression pattern in different subsets of neuronal progenitors dictates the outcome of pathway modulation. Following exit from the cell cycle, cortical neurons migrate along the processes of the radial glia to reach the cortical plate. Knockdown or knockout of Serping1 impairs radial migration. The delay in reaching the cortical plate did not affect cell identity, and the stalled cells express CUX1 similar to the control cells. Migration delay is transient and in the postnatal brain, the cells eventually reach the cortical plate. Interestingly, Serping1 knockdown affected not only the manipulated cells but also their neighbors; thus it is working both in a cell autonomous and a non-cell autonomous 

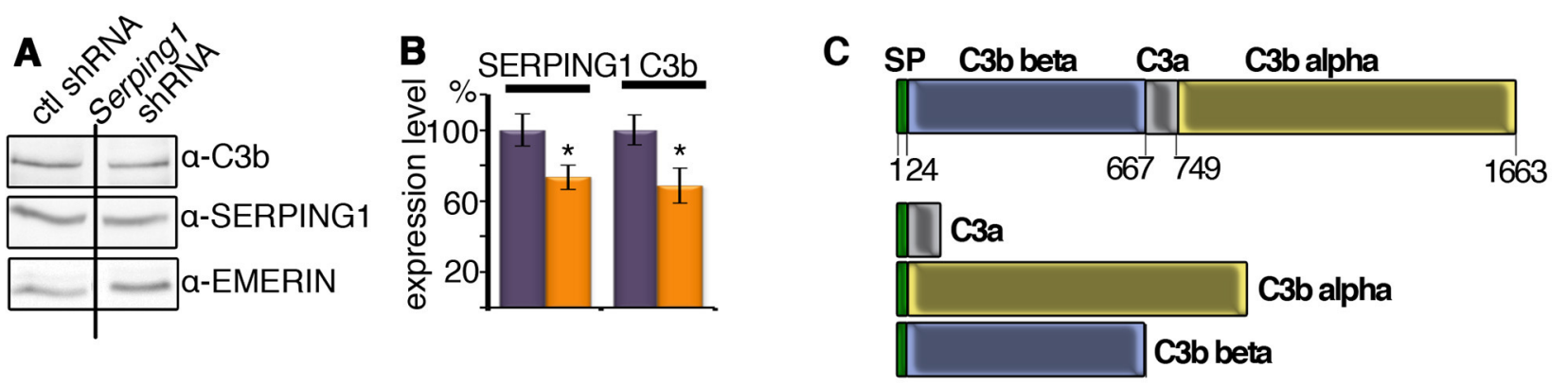

\section{Serping1 shRNA Serping1 shRNA $+\mathrm{C} 3 a$}
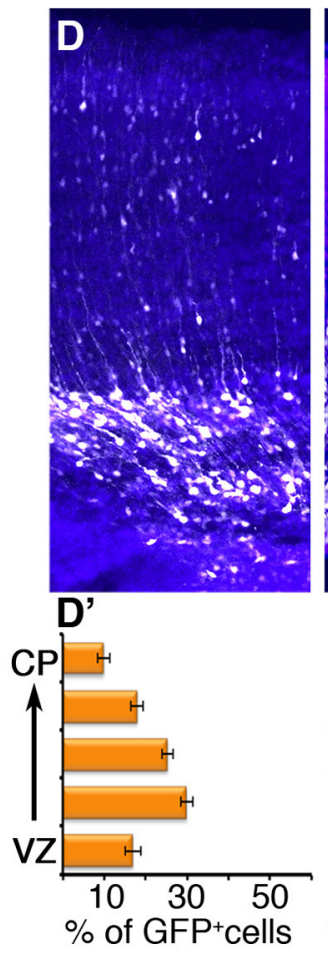
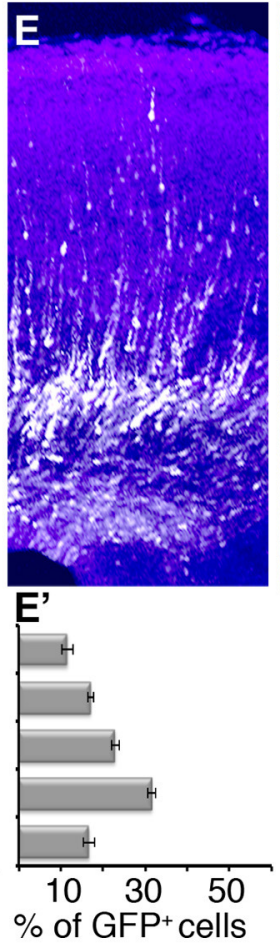
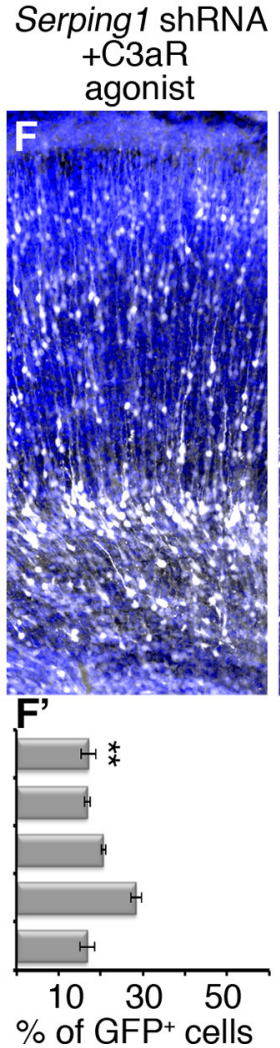

\section{Serping 1 shRNA
+ +C3b alpha}
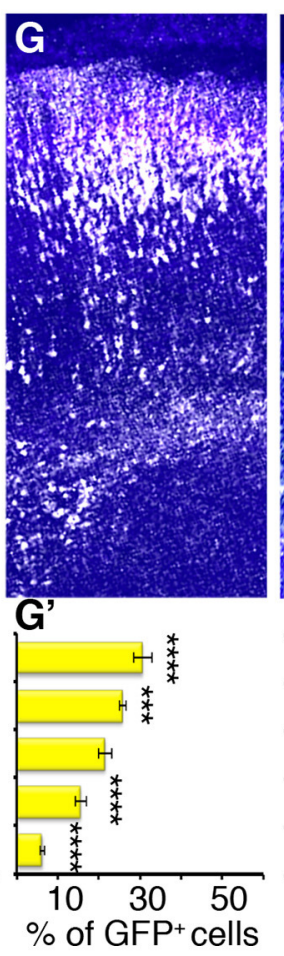

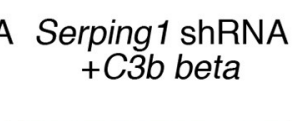

A Serping 1 shRNA
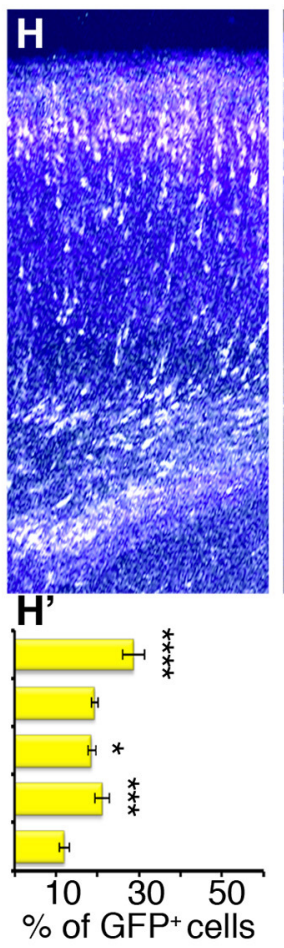

$+\mathrm{C} 3 \mathrm{aR} / \mathrm{C} 5 \mathrm{aR}$ agonist

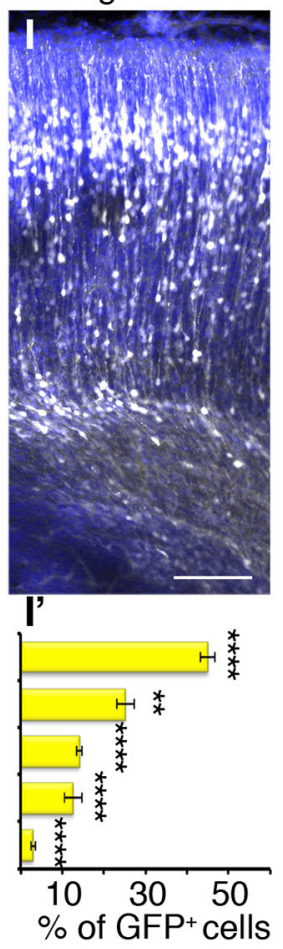

FIGURE 6 | Serping1 in the complement pathway. (A,B) Levels of activated C3 (C3b) are slightly reduced in the Serping1 shRNA compared to control. Areas from the brains electroporated in utero on E14 with control or Serping1 shRNA were dissected on E17 and subjected to western blot analysis with anti-C3b antibodies, anti-SERPING1 and anti-EMERIN antibodies. The levels of SERPING1 and C3b were normalized to EMERIN and quantified $(n=9)$. ${ }^{*} p<0.05$. (C) Schematic representation of C3. The proteolytic cleavage of C3 on aa 667 and aa 749 results in C3a peptide and C3b, composed of two subunits: C3b beta and C3b alpha. Three fragments mimicking the cleavage products of C3, all with an N-terminal signal peptide (SP, green). (D-I) Rescue of Serping1 shRNA migration phenotype with C3 fragments and peptides, agonists of Complement receptors. Brains were electroporated (E14-E18) with Serping1 shRNA alone (D) or together with either C3a (E), C3aR agonist (F), С3b alpha (G), C3b beta $(\mathbf{H})$, or dual C3aR/C5aR agonist (I). The scale bar is $100 \mu \mathrm{m}$. The distribution of neurons along the cortex in 5 bins is shown (D'-I'). All conditions were compared to Serping1 shRNA. Two-way ANOVA, $n=11,{ }^{\star} p<0.05,{ }^{* \star} p<0.01,{ }^{\star \star \star} p<0.001,{ }^{\star \star \star *} p<0.0001$.

way. The cell autonomous and non-cell autonomous effect was noticed not only on the position of the cells in the developing cerebral cortex, but was also seen in the cellular morphology of the neighboring cells. Serping1 knockdown cells exhibited long leading processes, which were also observed in near neighbors. These extended processes may be due to elevated levels of the microtubule-associated protein MAP2, which was detected by western blot analysis of brain lysates. The non-cell autonomous effects may be of particular interest when considering the possibilities of somatic mutations in the developing brain. The notion that somatic mutations play an important role in human disease has been widely accepted in case of cancer, in which even genetic mutations usually require a second somatic hit to initiate the development of tumors (Hanahan and Weinberg, 2000). Furthermore, conceptual progress in the last decade allows us to assimilate that participation in disease progression 
is not restricted to the very cells that are mutated, but also to the adjacent "healthy" tissue which changes its properties as a consequence of the presence of the mutated cells (review Hanahan and Weinberg, 2011). Emerging evidence suggest that somatic mutations may also participate in brain diseases (review Gleeson et al., 2000). Perhaps one of best-known examples is DCX, an X-linked gene (des Portes et al., 1998; Gleeson et al., 1998), in which mutations result in lissencephaly in males and a "doublecortex" phenotype in females due to random Xinactivation. On the other hand, somatic mutations in the same gene in males result in the "doublecortex" phenotype (Gleeson et al., 2000). Serping1 non-cell autonomous effects then adds on to another gene characterized from the same screen Atx, which also exhibited non-cell autonomous effects (Greenman et al., 2015).

\section{The Role of Serping1 in Migrating Neurons in Relation to the Complement Pathway}

Our unbiased screen for molecules, which participate in noncell autonomous regulation of neuronal migration revealed Serping1 as a molecule, which is differentially expressed and allowed us to uncover an unexpected role of the innate immune complement pathway in the regulation of neuronal migration (Gorelik et al., 2017). There may be several possible reasons as for why this pathway has been recruited to function in a noncell autonomous fashion in the developing brain. The pathway consists of a cascade of proteases, coupled with many inherent regulatory steps. Many of the pathway components are secreted or bound to the cell surface, ideal for cell-cell communication (reviews Walport, 2001; Fujita, 2002; Rutkowski et al., 2010; Stephan et al., 2012). As opposed to cell destruction induced by the complement pathway in response to pathogens (Fujita, 2002), this pathway has a vital role in migrating neurons. Based on our data, we suggest that activation of the pathway may result in reshaping of cells, possibly via partial opsonization, or tagging of multipolar neurites, enabling the polarity transition of neurons toward successful migration along radial glia. Our experimental results also indicate that the developing brain uses components of the complement in a non-orthodox way, as knockdown of Serping1 did not trigger activation of the pathway. However, the C3a peptide, or a C3a receptor agonist did not rescue neuronal positioning following Serping1 shRNA mediated knockdown. These results are different from those obtained following knockdown of Masp2, C3, or in C3 KO mice, where either the single or the dual agonists rescued migration (Gorelik et al., 2017). C3a has been demonstrated to act as a chemoattractant during collective cell migration of neural crest cells (Carmona-Fontaine et al., 2011) and enteric neural crest cells (Broders-Bondon et al., 2016). In case of in Serping1 shRNA treatments, fragments mimicking $\mathrm{C} 3$ cleavage (C3b beta and alpha) rescued the migration impairment neurons. Moreover, our data indicate that signaling is likely to be also transmitted through the complement C5a receptors, which when activated, completely rescued neuronal migration deficits observed in the case of Serping1 knockdown. It should be noted that this study could not distinguish between a role for $\mathrm{C} 5 \mathrm{a}$ receptor
1 or C5a receptor 2 (C5L2). However, it has been previously demonstrated that perturbations in $\mathrm{C} 5$ a receptor 1 signaling during rodent brain development can result in select neuronal defects (Benard et al., 2008; Denny et al., 2013; Coulthard et al., 2017), possibly indicating a predominant role for this receptor subtype in embryonic development (Hawksworth et al., 2014). Regardless, our study adds to the evidence for widespread roles for complement fragments $\mathrm{C} 3 \mathrm{a}$ and $\mathrm{C} 5 \mathrm{a}$ in development (Hawksworth et al., 2016).

The complement system is indeed a complex pathway with three "linear" arms that converge but also interconnect at several point. We therefore cannot be confident about the exact regulatory mechanism and possible positive and negative feedback loops in which Serping1 relates to the pathway in the context of progenitor proliferation and neuronal migration. In many respects, this process exhibits analogies to the previously described role of the complement pathway in successful elimination of excess numbers of synapses, which is developmentally regulated (Stevens et al., 2007; Schafer et al., 2012). Other components of the immune system, such as the major histocompatibility complex (MHC) and many others, have been shown to play a role in the developing brain (reviews Boulanger and Shatz, 2004; Boulanger, 2009). Furthermore, the uniqueness and unexpected results following Serping1 knockdown may be due to additional activities of this potent molecule beside the complement system (Davis et al., 2008), which should be investigated in the future.

\section{METHODS AND MATERIALS}

\section{Plasmids and Primers}

The following shRNA constructs were cloned into pSuper vector (Brummelkamp et al., 2002): Dcx shRNA1 (5' - GCTCAAGTG ACCACCAAGGCTAT) (Bai et al., 2003); Dclk shRNA1 (5' - GGT TCGATTCTAC AGAAAT) (Koizumi et al., 2006). The following shRNA was purchased from OpenBiosystems (ThermoScientific) in pLKO.1 vector: Serping1 shRNA (5' - CCTGACGATGCCTCA TATAA). The control shRNA plasmid used is pLKO.1-TRC control (Addgene) containing non-hairpin $18 \mathrm{bp}$ sequence $\left(5^{\prime}\right.$ CCGCAGGTATGCAACGCG).

A plasmid containing the complete coding sequences of Serping1 (BC002026.1) was purchased from OpenBiosystems (ThermoScientific) and subcloned into pCAGGS plasmid. This plasmid was used as a basis for creating shRNA resistant plasmids. 4 mismatches with the shRNA sequence were inserted in the original sequences by PCR using the following primer: 5'- AAGCTCGAGCTGTCCAAATTCCTG CCCACTTACCTACCA TGCCACACATAAAGT (Serping1).

A plasmid containing the complete coding sequences of C3 (BC043338.1) was purchased from OpenBiosystems (ThermoScientific). C3a was subcloned from the C3 plasmid with following primers: 5'- ATATGGCTAGCTCAGTACAGT TGATGGAAA and 5' - ATAGCGGCCGCTCACCTGGCCAGG CCCAGCACG. C3b beta was subcloned from the C3 plasmid with following primers: 5'- ATATGGCTAGCATCCCCATGT ATTCCATCATT and 5'- ATAGCGGCCGCTCAGGCTGCT GGCTTGGTGCACTC. C3b alpha was subcloned from the C3 
plasmid with following primers: 5' - ATATGGCTAGCATCC CCATGTATTCCATCATT and 5' - ATAGCGG CCGCTCAGT TGGGACAACCATAAAC. The C3 fragments were subcloned into the pCAGGS plasmid that contained C3 signal peptide (5' - ATGGGGGACCAGCTTCAGGGTCCCAGCTACTAGTGC TACTGCTGCTGTTGGCCAGCTCCCCATTAGCTCTGGGG).

For Real-Time PCR of Serping1 the following primers were used: 5'- GCCCAATTCGATGACCATAC and 5'- AAGTTG GTGCTTTGGGAACA; 5' - GCCCAATTCGATGACCATAC and 5'-AGTGGGGTTGAGAGCCTTTT; 5' -TTCCCTGAA AGAGATGACTCCTGGA and $5^{\prime}$ - CGTTGGCTACTTTAC CCATGGTGTC; 5' - TGGAGTCCCCCAGAGCCTACA and 5' GAGGAGGCTGGCAATGCTGA. 29rps primers were used as a reference: 5' - GTATTTGCGGATCAGACCGT and 5' - CTG AAGGCAAGATGGGTCA.

For PCR of Serping1 cDNA the following primers were used: 5'- AGAGAGCTTCCCTGAAAGAGATG and 5'- TGA GGAGGCTGGCAATGCTGA.

\section{Antibodies}

Rabbit anti SERPING1/C1INH (Santa Cruz, H-300, 1:250), rabbit anti EMERIN (Santa Cruz, FL-254, 1:1,000), mouse antiMAP2 (Sigma-Aldrich, HM-2, 1:500), rat anti C3b antibodies (Hycult Biotech, 1:500, HM1065) were used for western blotting.

The following antibodies were used for immunostainings: chicken anti TBR2 (Millipore, 1:100, AB15894), rabbit anti CUX1 (anti CDP, Santa Cruz, 1:100, SC-13024), chicken anti TBR1 (Millipore, 1:100, AB2261), mouse anti IdU-B44 (BD Biosciences, 1:200, 347580), chicken anti GFP (Abcam, 1:1000). Mouse CTR433 antibodies (1:50, Jasmin et al., 1989), a Golgi marker, was kindly provided by Dr. Michel Bornens (Institute Curie, Paris, France).

\section{Complement Agonist Peptides}

The selective C3aR agonist, WWGKKYRASKLGLAR ("superagonist” Wu et al., 2013), and a C5aR agonist, YSFKPMPLaR ("EP54" Woodruff et al., 2001) were synthesized as previously described (Woodruff et al., 2001; Wu et al., 2013). It should be noted that the C5aR agonist also activates C3aR (Scully et al., 2010) and thus is described herein as a dual C3aR/C5aR agonist. The agonists $(1 \mu \mathrm{g} / \mathrm{mg})$ were injected to the ventricles of the embryos together with the indicated plasmids.

\section{Animals}

Animal protocols were approved by the Weizmann Institute IACUC and were carried out in accordance with their approved guidelines. ICR mice were purchased from Harlan laboratories. Male and female embryos were used in the study.

\section{CRISPR/Cas9 Knockout Generation}

Cas9 plasmid and plasmids encoding guide RNAs were purchased from the University of Utah Mutation Generation lab. The following oligonucleotides were used for construction of gRNA vectors:

1. Serping1: $5^{\prime}$ ACACCGGCTACACTGGTTGTTGGCCG and $5^{\prime}$ AAAACGGCCAACAACCAGTGTAGCCG (location 2:24847967-24847990: + strand);
In vitro transcribed Cas9 $\mathrm{RNA}(100 \mathrm{ng} / \mathrm{ul})$, and sg RNA(50 $\mathrm{ng} / \mathrm{ul})$, were injected into one cell fertilized embryos isolated from superovulated $\mathrm{CB} 6 \mathrm{~F} 1$ hybrid mice mated with $\mathrm{CB} 6 \mathrm{~F} 1$ males Harlan Biotech Israel Ltd. (Rehovot, Israel). Injected embryos were transferred into the oviducts of pseudopregnant ICR females as previously described (Wang et al., 2013). For migration analysis the pregnant mice were subjected to IdU injection at E14.5 and sacrificed at E18. Genomic DNA from the treated embryos was analyzed for mutations in the mutated genes using High Resolution Melt (HRM) analysis and confirmed by Sanger sequencing. For the proliferation analysis the mice from established mouse line were used. The genotype verification was performed with the following primers: $5^{\prime}$ - TTCCCTGAAAGA GATGACTCCTGGA and 5' - CGTTGGCTACTTTACCCATGG TGTC.

\section{IdU Injection}

The thymidine analog iododeoxyuridine (IdU) was injected intraperitoneally $(0.01 \mathrm{ml}$ of $5 \mathrm{mg} / \mathrm{ml}$ IdU solution per gram body weight) into pregnant mice at the indicated time points.

\section{EdU Labeling and Click Chemistry}

For labeling cells in S phase, pregnant mice (E14) were injected with $(50 \mathrm{mg} / \mathrm{gr}$ body weight) 5-ethynyl-2'-deoxyuridine (EdU) solution and were scarified $30 \mathrm{~min}$ post-injection. The brains were removed and fixed in 2.5\% PFA-PBS overnight, washed and cryoporotected by immersion in $30 \%$ sucrose-PBS solution. The cryosections $(10 \mu \mathrm{m})$ were pretreated in boiling sodium citrate buffer $(10 \mathrm{mM}, \mathrm{pH}$ 6) for $30 \mathrm{~min}$. The click reaction was performed with $\mathrm{Cy} 3$ azide $(2.5 \mu \mathrm{M})$ in the PBS-based buffer containing $100 \mathrm{mM}$ Tris- $\mathrm{HCl}, 1 \mathrm{mM} \mathrm{CuSO}_{4}$, and $100 \mathrm{mM}$ ascorbic acid. This reaction was followed by a click reaction with a non-fluorescent molecule (Phenylthiomethyl-Azide $20 \mathrm{mM}$, SIGMA). After treatment with $10 \mathrm{mM}$ ascorbic acid and $4 \mathrm{mM}$ $\mathrm{CuSO}_{4}$, followed by incubation with $20 \mathrm{mM}$ EDTA, the relevant immunostainings were performed.

\section{In utero Electroporation}

Plasmids were transfected by in utero electroporation using previously described methods (Saito and Nakatsuji, 2001; Tabata and Nakajima, 2001). Prior to surgery the animals were injected with buprenorphine ( $2 \mathrm{mg} / \mathrm{Kg} \mathrm{BW}$, subcutaneously). Pregnant ICR mice at E14.5 days post-gestation (E14), were anesthetized by injection of ketamine $10 \%$ /xylazine $20 \mathrm{mg} / \mathrm{ml}$ (1/10 mixture, $0.01 \mu \mathrm{l}$ per $\mathrm{g}$ of body weight, intraperitoneally), alternatively Isofluran anesthesia was used. The uterine horns were exposed, and plasmid mixed with Fast Green ( $2 \mu \mathrm{g} / \mu \mathrm{l}$, Sigma) were microinjected through the uterus into the lateral ventricles of embryos by pulled glass capillaries (Sutter Instrument, Novato, CA). The concentration of plasmids was $0.5 \mu \mathrm{g} / \mu \mathrm{l}$ for pCAGGS-GFP, $2 \mu \mathrm{g} / \mu \mathrm{l}$ for shRNA construct and 1-1.5 $\mu \mathrm{g}$ for overexpression plasmids. Electroporation was accomplished by discharging five $41 \mathrm{mV} 50 \mathrm{~ms}$ long pulses with $950 \mathrm{~ms}$ intervals, generated by a NepaGene electroporator. The pulses were delivered using $10 \mathrm{~mm}$ diameter platinum plated tweezers electrodes (Protech international Inc., San Antonio, TX) placed at either side or the head of each through the uterus. Animals 
were sacrificed 4 days after electroporation at E18.5 (E18). Embryos with well-distinctive positive GFP signal in cortex visible through fluorescent binocular were intracardially perfused using $4 \%$ paraformaldehyde-phosphate buffered saline (PFAPBS). Embryos with dotted, double hit or hit outside the cortex were not included in the study. Brains were post-fixed overnight and sectioned (60 $\mu \mathrm{m}$; vibrotome, Leica). For examination of long-term effects of the treatments in utero electroporation was performed at E14, the mice delivered and the pups of postnatal day 8 (P8) were used for the experiments. For proliferation experiments embryos were in utero electroporated on E13.5 (E13) with $7 \mathrm{~mm}$ electrodes (39 $\mathrm{mV}$ pulses). IdU was injected in $24 \mathrm{~h}$ after electroporation for $30 \mathrm{~min}$. Post-fixed brains were cryopreserved in sucrose and cryosections $(10 \mu \mathrm{m})$ were used for proliferation analysis. For double electroporation the first in utero electroporation was performed at E13.5 with $7 \mathrm{~mm}$ electrodes ( $39 \mathrm{mV}$ pulses). The second electroporation was performed $24 \mathrm{~h}$ later as described above.

\section{Immunocytochemistry}

Floating vibratome sections $(60 \mu \mathrm{m})$ were permeabilized using $0.1 \%$ Triton X-100 and blocked in blocking solution (PBS, $0.1 \%$ Triton X-100, 10\% HS; 10\% FBS) for $60 \mathrm{~min}$. Antibodies were incubated in blocking solution over night at $4{ }^{\circ} \mathrm{C}$. After washing, appropriate secondary antibodies (Jackson ImmunoResearch) were diluted in blocking solution, and incubated for $2 \mathrm{~h}$ at room temperature. Slices were mounted onto glass slides using Aqua Polymount (Polysciences). For IdU immunostainings (E18) the brain slices were pretreated with $\mathrm{HCl}$ (30') followed by neutralization with borate buffer. For IdU immunostainings (E13 and E14) the cryosections $(10 \mu \mathrm{m})$ were used. Antigen retrieval procedure was performed by boiling slides in sodium citrate buffer $(10 \mathrm{mM}, \mathrm{pH} 6)$ for $30 \mathrm{~min}$.

\section{Microscopy, Quantification, and Statistical Analyses}

Images were taken using confocal microscopy (LSM780, LSM800 Zeiss), equipped with Axio Observer Z1 microscope, and imaged with either Plan-apochromat $20 \mathrm{x} / 0.8$, or Planapochromat $40 \mathrm{x} / 1.2$, or Plan-apochromat $63 \mathrm{x} / 1.4$ oil objectives. The scaling data are $0.624 \mathrm{X} 0.624 \mu \mathrm{m}$ per pixel for $20 \mathrm{X}$ magnification, $0.312 \mathrm{X} 0.312 \mu \mathrm{m}$ per pixel for $40 \mathrm{X}$ magnification, and $0.198 \mathrm{X} 0.198 \mathrm{X} 0.51 \mu \mathrm{m}$ per voxol for 60X magnification. The images were processed by ZEN software and/or Imaris software.

Cell count, positioning and colocalization analyses were performed using Imaris software (Bitplane Inc., Zurich, Switzerland, Imaris core module). At least three brains were analyzed for each treatment. Four representative slices from each brain were chosen for analysis. The size of the area of interest was determined and preserved per each experiment. For each slice the area of interest was positioned so that the center of the electroporated area is in the center of the area of interest. For the cell count and positioning the relevant channel of an area of interest was analyzed with "Spots" module of Imaris, every spot labeling approximate center of the cell body. The " $y$ " position of all the dots was analyzed by Microsoft Excel Histogram tool.
The data were presented in percentages out of total analyzed cells per bin. For Figure 1B an average of $135.6 \pm 8.3$ (control shRNA) and $129 \pm 15.4$ (Serping1 shRNA) GFP-positive cells were analyzed per each slice. For Figure 2D an average of 490.8 \pm 44.1 (control shRNA), $704 \pm 51.8$ (Serpingl shRNA), and $662.1 \pm 52.8$ (Serping1 shRNA +Serping1res) GFP-positive cells were analyzed per slice. For Figure 2G an average of 249.5 \pm 12.4 (WT) and $259.5 \pm 13.6$ (Serping1 KO) IdU-positive cells were analyzed per slice. For Figure 3 an average of 175.6 \pm 14.3 (Figure 3A'), $180 \pm 12.5$ (Figure 3B'), $267.6 \pm 37$ (Figure 3D'), $182 \pm 17.2$ (Figure 3E'), $174.6 \pm 19.5$ (Figure 3G'), $137.1 \pm 11.5$ (Figure 3H'), $111.7 \pm 9.3$ (Figure 3J'), $166 \pm 13.3$ (Figure 3K'), $112 \pm 21$ (Figure 3N') GFP- or dsRed-positive cells were analyzed per slice. For Supplementary Figure 4C an average of $275.1 \pm 24.5$ (electroporated side) and $226.7 \pm$ 30.9 (non-electroporated side) cells were analyzed per slice. Statistical analysis was performed by Student's or Welch's $t$-tests or one-way or two-way analysis of variance (ANOVA) followed by Bonferroni multiple comparison analysis, using PRISM 7 for Mac (GraphPad software). Error bars represent standard error. For the measurement of leading edge length high resolution z-stack images were collected of the relevant slices. The analysis was performed with the ImageJ program.

\section{Real-Time qRT-PCR}

For confirmation of shRNA efficiency neurospheres from E13.5 were grown in Neurobasal medium (Gibco) supplemented with B27, glutamax, gentamicine, EGF (20 ng/ml), bFGF $(20 \mathrm{ng} / \mathrm{ml})$, and heparin for 2 days. The cells were transfected by NEPA21 electroporator (Nepagene) according to manufacturer's instructions. The cells were grown for additional $48 \mathrm{~h}$ and collected for RNA isolation (TRI reagent, Sigma). After Dnase treatment (Sigma), first-strand cDNA synthesis was done using M-MLV RT (Promega). Relative levels of Serping1 expression were normalized to the 29rps gene. Real-time PCR with SYBR FAST ABI qPCR kit (Kapa Biosystems) was performed using StepOnePlus Real-Time PCR System (Applied Biosystems). E13, E14, E16, E18 cortices ( $n=6$ for each time point) were dissected in cold PBS and fast-freeze in liquid nitrogen. RNA preparation and Real-time RT-PCR were performed as described above.

\section{Western Blot}

Brains were in utero electroporated with control shRNA or Serping1 shRNA together with GFP (E14-E17). The electroporated areas were dissected under fluorescent binocular. The dissected areas were homogenized in lysis buffer $(50 \mathrm{mM}$ Tris-HCl pH7.5; 150 mM NaCl; 1 mM EDTA; 1 mM EGTA; 1\% Triton X-100) supplemented with protease inhibitor cocktail (Sigma). Fifty microgram of total protein was mixed with SDS sample buffer, separated by SDS-PAGE and subjected to western blot analysis with the indicated antibodies.

\section{AUTHOR CONTRIBUTIONS}

AG and TS planned, conducted experiments, analyzed data, and wrote the manuscript. TW contributed receptor agonists, 
planned experiments, and wrote the manuscript. OR planned experiments, analyzed the data, and wrote the manuscript.

\section{FUNDING}

The research has been supported by the Israel Science Foundation (grant no. 347/15), the Legacy Heritage Biomedical Program of the Israel Science Foundation (grant no. 322/13), Weizmann-FAPESP supported by a research grant from the Dr. Beth Rom-Rymer Stem Cell Research Fund, Nella and Leon Benoziyo Center for Neurological Diseases, Yeda-Sela Center for Basic Research, Jeanne and Joseph Nissim Foundation for Life Sciences Research, Wohl Biology Endowment Fund, Fritz Thyssen Stiftung, Lulu P. and David J. Levidow Fund for Alzheimers Diseases and Neuroscience Research the Helen and Martin Kimmel Stem Cell Research Institute, the Kekst Family Institute for Medical Genetics, the David and Fela Shapell Family Center for Genetic Disorders Research. TW is supported

\section{REFERENCES}

Akuffo, E. L., Davis, J. B., Fox, S. M., Gloger, I. S., Hosford, D., Kinsey, E. E., et al. (2008). The discovery and early validation of novel plasma biomarkers in mild-to-moderate Alzheimer's disease patients responding to treatment with rosiglitazone. Biomarkers 13, 618-636. doi: 10.1080/135475008024 45199

Bai, J., Ramos, R. L., Ackman, J. B., Thomas, A. M., Lee, R. V., and LoTurco, J. J. (2003). RNAi reveals doublecortin is required for radial migration in rat neocortex. Nat. Neurosci. 6, 1277-1283. doi: 10.1038/nn1153

Benard, M., Raoult, E., Vaudry, D., Leprince, J., Falluel-Morel, A., Gonzalez, B. J., et al. (2008). Role of complement anaphylatoxin receptors (C3aR, C5aR) in the development of the rat cerebellum. Mol. Immunol. 45, 3767-3774. doi: 10.1016/j.molimm.2008.05.027

Boulanger, L. M. (2009). Immune proteins in brain development and synaptic plasticity. Neuron 64, 93-109. doi: 10.1016/j.neuron.2009.09.001

Boulanger, L. M., and Shatz, C. J. (2004). Immune signalling in neural development, synaptic plasticity and disease. Nat. Rev. Neurosci. 5, 521-531. doi: 10.1038/nrn1428

Bowen, T., Cicardi, M., Farkas, H., Bork, K., Longhurst, H. J., Zuraw, B., et al. (2010). 2010 International consensus algorithm for the diagnosis, therapy and management of hereditary angioedema. Allergy Asthma Clin. Immunol. 6:24. doi: 10.1186/1710-1492-6-24

Broders-Bondon, F., Paul-Gilloteaux, P., Gazquez, E., Heysch, J., Piel, M., Mayor, R., et al. (2016). Control of the collective migration of enteric neural crest cells by the Complement anaphylatoxin C3a and N-cadherin. Dev. Biol. 414, 85-99. doi: 10.1016/j.ydbio.2016.03.022

Brummelkamp, T. R., Bernards, R., and Agami, R. (2002). A system for stable expression of short interfering RNAs in mammalian cells. Science 296, 550-553. doi: 10.1126/science.1068999

Carmona-Fontaine, C., Theveneau, E., Tzekou, A., Tada, M., Woods, M., Page, K. M., et al. (2011). Complement fragment C3a controls mutual cell attraction during collective cell migration. Dev. Cell 21, 1026-1037. doi: 10.1016/j.devcel.2011.10.012

Chiam, J. T., Dobson, R. J., Kiddle, S. J., and Sattlecker, M. (2015). Are blood-based protein biomarkers for Alzheimer's disease also involved in other brain disorders? A systematic review. J. Alzheimer's Dis. 43, 303-314. doi: 10.3233/JAD-140816

Coulthard, L. G., Hawksworth, O. A., Li, R., Balachandran, A., Lee, J. D., Sepehrband, F., et al. (2017). Complement C5aR1 signaling promotes polarization and proliferation of embryonic neural progenitor cells through

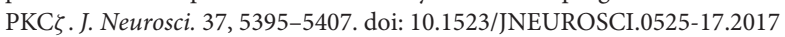

by a National Health and Medical Research Council Career Development Fellowship (APP1105420).

\section{ACKNOWLEDGMENTS}

We are grateful for the help of Rebecca Haffner-Krausz, Golda Damari, Alina Maizenberg, Sima Peretz, Ofira Higfa, Yehuda Melamed, Osnat Amram, Oz Yirmiyahu, and Sergey Viukov from the Weizmann Institute of Science, Allison R. Bialas and Beth Stevens from the Children's Hospital, Harvard Medical School, Boston and Timothy Dahlem, Utah University. OR is the incumbent of the Bernstein-Mason Chair of Neurochemistry.

\section{SUPPLEMENTARY MATERIAL}

The Supplementary Material for this article can be found online at: http://journal.frontiersin.org/article/10.3389/fncel. 2017.00169/full\#supplementary-material

Cutler, P., Akuffo, E. L., Bodnar, W. M., Briggs, D. M., Davis, J. B., Debouck, C. M., et al. (2008). Proteomic identification and early validation of complement 1 inhibitor and pigment epithelium-derived factor: Two novel biomarkers of Alzheimer's disease in human plasma. Proteomics Clin. Appl. 2, 467-477. doi: 10.1002/prca.200780101

Davis, A. E., Mejia, P., and Lu, F. (2008). Biological activities of C1 inhibitor. Mol. Immunol. 45, 4057-4063. doi: 10.1016/j.molimm.2008.06.028

De Simoni, M. G., Rossi, E., Storini, C., Pizzimenti, S., Echart, C., and Bergamaschini, L. (2004). The powerful neuroprotective action of C1-inhibitor on brain ischemia-reperfusion injury does not require C1q. Am. J. Pathol. 164, 1857-1863. doi: 10.1016/s0002-9440(10)63744-3

Denny, K. J., Coulthard, L. G., Jeanes, A., Lisgo, S., Simmons, D. G., Callaway, L. K., et al. (2013). C5a receptor signaling prevents folate deficiency-induced neural tube defects in mice. J. Immunol. 190, 3493-3499. doi: 10.4049/jimmunol.1203072

des Portes, V., Pinard, J. M., Billuart, P., Vinet, M. C., Koulakoff, A., Carrie, A., et al. (1998). A novel CNS gene required for neuronal migration and involved in X-linked subcortical laminar hetrotropia and lissencephaly syndrome. Cell 92, 51-61. doi: 10.1016/S0092-8674(00)80898-3

Dinsmore, J. H., and Solomon, F. (1991). Inhibition of MAP2 expression affects both morphological and cell division phenotypes of neuronal differentiation. Cell 64, 817-826. doi: 10.1016/0092-8674(91)90510-6

Fujita, T. (2002). Evolution of the lectin-complement pathway and its role in innate immunity. Nat. Rev. Immunol. 2, 346-353. doi: 10.1038/nri800

Gesuete, R., Storini, C., Fantin, A., Stravalaci, M., Zanier, E. R., Orsini, F., et al. (2009). Recombinant C1 inhibitor in brain ischemic injury. Ann. Neurol. 66, 332-342. doi: 10.1002/ana.21740

Gleeson, J. G., Allen, K. M., Fox, J. W., Lamperti, E. D., Berkovic, S., Scheffer, I., et al. (1998). Doublecortin, a brain-specific gene mutated in human X-linked lissencephaly and double cortex syndrome, encodes a putative signaling protein. Cell 92, 63-72. doi: 10.1016/s0092-8674(00) 80899-5

Gleeson, J. G., Minnerath, S., Kuzniecky, R. I., Dobyns, W. B., Young, I. D., Ross, M., et al. (2000). Somatic and germline mosaic mutations in the doublecortin gene are associated with variable phenotypes. Am. J. Hum. Genet. 67, 574-581. doi: $10.1086 / 303043$

Gorelik, A., Sapir, T., Haffner-Krausz, R., Olender, T., Woodruff, T. M., and Reiner, O. (2017). Developmental activities of the complement pathway in migrating neurons. Nat. Commun. 8:15096. doi: 10.1038/ncomms15096

Greenman, R., Gorelik, A., Sapir, T., Baumgart, J., Zamor, V., Segal-Salto, M., et al. (2015). Non-cell autonomous and non-catalytic activities of ATX in the developing brain. Front. Neurosci. 9:53. doi: 10.3389/fnins.2015.00053 
Han, E. D. (2002). Increased vascular permeability in C1 inhibitor-deficient mice mediated by the bradykinin type 2 receptor. J. Clin. Investig. 109, 1057-1063. doi: $10.1172 /$ jci200214211

Hanahan, D., and Weinberg, R. A. (2000). The hallmarks of cancer. Cell 100, 57-70. doi: 10.1016/S0092-8674(00)81683-9

Hanahan, D., and Weinberg, R. A. (2011). Hallmarks of cancer: the next generation. Cell 144, 646-674. doi: 10.1016/j.cell.2011.02.013

Hawksworth, O. A., Coulthard, L. G., and Woodruff, T. M. (2016). Complement in the fundamental processes of the cell. Mol. Immunol. 84, 17-25. doi: 10.1016/j.molimm.2016.11.010

Hawksworth, O. A., Coulthard, L. G., Taylor, S. M., Wolvetang, E. J., and Woodruff, T. M. (2014). Brief report: complement C5a promotes human embryonic stem cell pluripotency in the absence of FGF2. Stem Cells 32, 3278-3284. doi: $10.1002 /$ stem. 1801

Heydenreich, N., Nolte, M. W., Gob, E., Langhauser, F., Hofmeister, M., Kraft, P., et al. (2012). C1-inhibitor protects from brain ischemia-reperfusion injury by combined antiinflammatory and antithrombotic mechanisms. Stroke 43, 2457-2467. doi: 10.1161/strokeaha.112.660340

Jasmin, B. J., Cartaud, J., Bornens, M., and Changeux, J. P. (1989). Golgi apparatus in chick skeletal muscle: changes in its distribution during end plate development and after denervation. Proc. Natl. Acad. Sci. U.S.A. 86, 7218-7222.

Jiang, H., Wagner, E., Zhang, H., and Frank, M. M. (2001). Complement 1 inhibitor is a regulator of the alternative complement pathway. J. Exp. Med. 194, 1609-1616. doi: 10.1084/jem.194.11.1609

Kawaguchi, A., Ikawa, T., Kasukawa, T., Ueda, H. R., Kurimoto, K., Saitou, M. (2008). Single-cell gene profiling defines differential progenitor subclasses in mammalian neurogenesis. Development 135, 3113-3124. doi: $10.1242 /$ dev.022616

Koizumi, H., Tanaka, T., and Gleeson, J. G. (2006). Doublecortin-like kinase functions with doublecortin to mediate fiber tract decussation and neuronal migration. Neuron 49, 55-66. doi: 10.1016/j.neuron.2005.1 0.040

Morgan, A. R., Touchard, S., O’Hagan, C., Sims, R., Majounie, E., EscottPrice, V., et al. (2017). The correlation between inflammatory biomarkers and polygenic risk score in alzheimer's disease. J. Alzheimer's Dis. 56, 25-36. doi: 10.3233/JAD-160889

Muenchhoff, J., Poljak, A., Song, F., Raftery, M., Brodaty, H., Duncan, M., et al. (2015). Plasma protein profiling of mild cognitive impairment and Alzheimer's disease across two independent cohorts. J. Alzheimer's Dis. 43, 1355-1373. doi: 10.3233/JAD-141266

Parej, K., Dobo, J., Zavodszky, P., and Gal, P. (2013). The control of the complement lectin pathway activation revisited: both $\mathrm{C} 1$-inhibitor and antithrombin are likely physiological inhibitors, while alpha2-macroglobulin is not. Mol. Immunol. 54, 415-422. doi: 10.1016/j.molimm.2013.0 1.009

Presanis, J. S., Hajela, K., Ambrus, G., Gál, P., and Sim, R. B. (2003). Differential substrate and inhibitor profiles for human MASP-1 and MASP-2. Mol. Immunol. 40, 921-929. doi: 10.1016/j.molimm.2003.10.013

Ran, F. A., Hsu, P. D., Wright, J., Agarwala, V., Scott, D. A., and Zhang, F. (2013). Genome engineering using the CRISPR-Cas9 system. Nat. Protoc. 8, 2281-2308. doi: 10.1038/nprot.2013.143

Rutkowski, M. J., Sughrue, M. E., Kane, A. J., Mills, S. A., Fang, S., and Parsa, A. T. (2010). Complement and the central nervous system: emerging roles in development, protection and regeneration. Immunol. Cell Biol. 88, 781-786. doi: $10.1038 /$ icb. 2010.48

Saito, T., and Nakatsuji, N. (2001). Efficient gene transfer into the embryonic mouse brain using in vivo electroporation. Dev. Biol. 240, 237-246. doi: $10.1006 /$ dbio.2001.0439
Schafer, D. P., Lehrman, E. K., Kautzman, A. G., Koyama, R., Mardinly, A. R., Yamasaki, R., et al. (2012). Microglia sculpt postnatal neural circuits in an activity and complement-dependent manner. Neuron 74, 691-705. doi: 10.1016/j.neuron.2012.03.026

Scully, C. C., Blakeney, J. S., Singh, R., Hoang, H. N., Abbenante, G., Reid, R. C., et al. (2010). Selective hexapeptide agonists and antagonists for human complement C3a receptor. J. Med. Chem. 53, 4938-4948. doi: $10.1021 / \mathrm{jm} 1003705$

Stephan, A. H., Barres, B. A., and Stevens, B. (2012). The complement system: an unexpected role in synaptic pruning during development and disease. Annu. Rev. Neurosci. 35, 369-389. doi: 10.1146/annurev-neuro-061010-113810

Stevens, B., Allen, N. J., Vazquez, L. E., Howell, G. R., Christopherson, K. S., Nouri, N., et al. (2007). The classical complement cascade mediates CNS synapse elimination. Cell 131, 1164-1178. doi: 10.1016/j.cell.2007.10.036

Storini, C., Rossi, E., Marrella, V., Distaso, M., Veerhuis, R., Vergani, C., De Simoni, M. G., et al. (2005). C1-inhibitor protects against brain ischemiareperfusion injury via inhibition of cell recruitment and inflammation. Neurobiol. Dis. 19, 10-17. doi: 10.1016/j.nbd.2004.11.001

Tabata, H., and Nakajima, K. (2001). Efficient in utero gene transfer system to the developing mouse brain using electroporation: visualization of neuronal migration in the developing cortex. Neuroscience 103, 865-872. doi: 10.1016/s0306-4522(01)00016-1

Veerhuis, R., Janssen, I., Hoozemans, J. J., De Groot, C. J., Hack, C. E., and Eikelenboom, P. (1998). Complement C1-inhibitor expression in Alzheimer's disease. Acta Neuropathol. 96, 287-296. doi: 10.1007/s004010050896

Walker, D. G., Yasuhara, O., Patston, P. A., McGeer, E. G., and McGeer, P. L. (1995). Complement C1 inhibitor is produced by brain tissue and is cleaved in Alzheimer disease. Brain Res. 675, 75-82. doi: 10.1016/0006-8993(95)00041-N

Walport, M. J. (2001). Complement. First of two parts. N. Engl. J. Med. 344, 1058-1066. doi: 10.1056/NEJM200104053441406

Wang, H., Yang, H., Shivalila, C. S., Dawlaty, M. M., Cheng, A. W., Zhang, F., et al. (2013). One-step generation of mice carrying mutations in multiple genes by CRISPR/Cas-mediated genome engineering. Cell 153, 910-918. doi: 10.1016/j.cell.2013.04.025

Woodruff, T. M., Strachan, A. J., Sanderson, S. D., Monk, P. N., Wong, A. K., Fairlie, D. P., et al. (2001). Species dependence for binding of small molecule agonist and antagonists to the $\mathrm{C} 5$ a receptor on polymorphonuclear leukocytes. Inflammation 25, 171-177. doi: 10.1023/A:1011036414353

Wu, M. C., Brennan, F. H., Lynch, J. P., Mantovani, S., Phipps, S., Wetsel, R. A., et al. (2013). The receptor for complement component C3a mediates protection from intestinal ischemia-reperfusion injuries by inhibiting neutrophil mobilization. Proc. Natl. Acad. Sci. U.S.A. 110, 9439-9444. doi: 10.1073/pnas.1218815110

Yasojima, K., McGeer, E. G., and McGeer, P. L. (1999). Complement regulators $\mathrm{C} 1$ inhibitor and $\mathrm{CD} 59$ do not significantly inhibit complement activation in Alzheimer disease. Brain Res. 833, 297-301. doi: 10.1016/S0006-8993(99)01514-0

Conflict of Interest Statement: The authors declare that the research was conducted in the absence of any commercial or financial relationships that could be construed as a potential conflict of interest.

Copyright (c) 2017 Gorelik, Sapir, Woodruff and Reiner. This is an open-access article distributed under the terms of the Creative Commons Attribution License (CC BY). The use, distribution or reproduction in other forums is permitted, provided the original author(s) or licensor are credited and that the original publication in this journal is cited, in accordance with accepted academic practice. No use, distribution or reproduction is permitted which does not comply with these terms. 